\title{
Spontaneous Pneumocephalus associated with a giant Craniopharyngioma
}

Vasiliki Daraki $^{1}$, Efrosini Papadaki ${ }^{2}$, Nikos Zampoulakis ${ }^{1}$, Evangelia Mamalaki ${ }^{1}$, George Kalikakis ${ }^{1}$ and Stathis Papavasiliou $^{1}$

${ }^{1}$ Department of Endocrinology, Diabetes and Metabolic Diseases, University Hospital of Crete, Heraklion, Greece.

${ }^{2}$ Department of Radiology, University Hospital of Crete, Heraklion, Greece.

\section{INTRODUCTION}

Pneumocephalus, also known as intracerebral aerocele or pneumatocele is defined as the presence of gas within any of the intracranial compartments of the cranial vault.

It is commonly encountered after neurosurgical procedures but can also be caused by craniofacial trauma and tumors of the skull base or infections with gasproducing organisms. Rarely, it can occur spontaneously.

Complications of tension pneumocephalus include intracranial air embolism and cardiac arrest or ascending meningitis in patients with CSF leaks, with an incidence of about $30 \%$ and a cumulative 10 -year risk of $85 \%$.

Although most collections are small, behave benign, and respond to conservative therapy, symptomatic cases may require urgent evaluation and treatment.
LATERAL RADIOGRAPH OF THE SKULL IN THE EMERGENCY DEPARTMENT

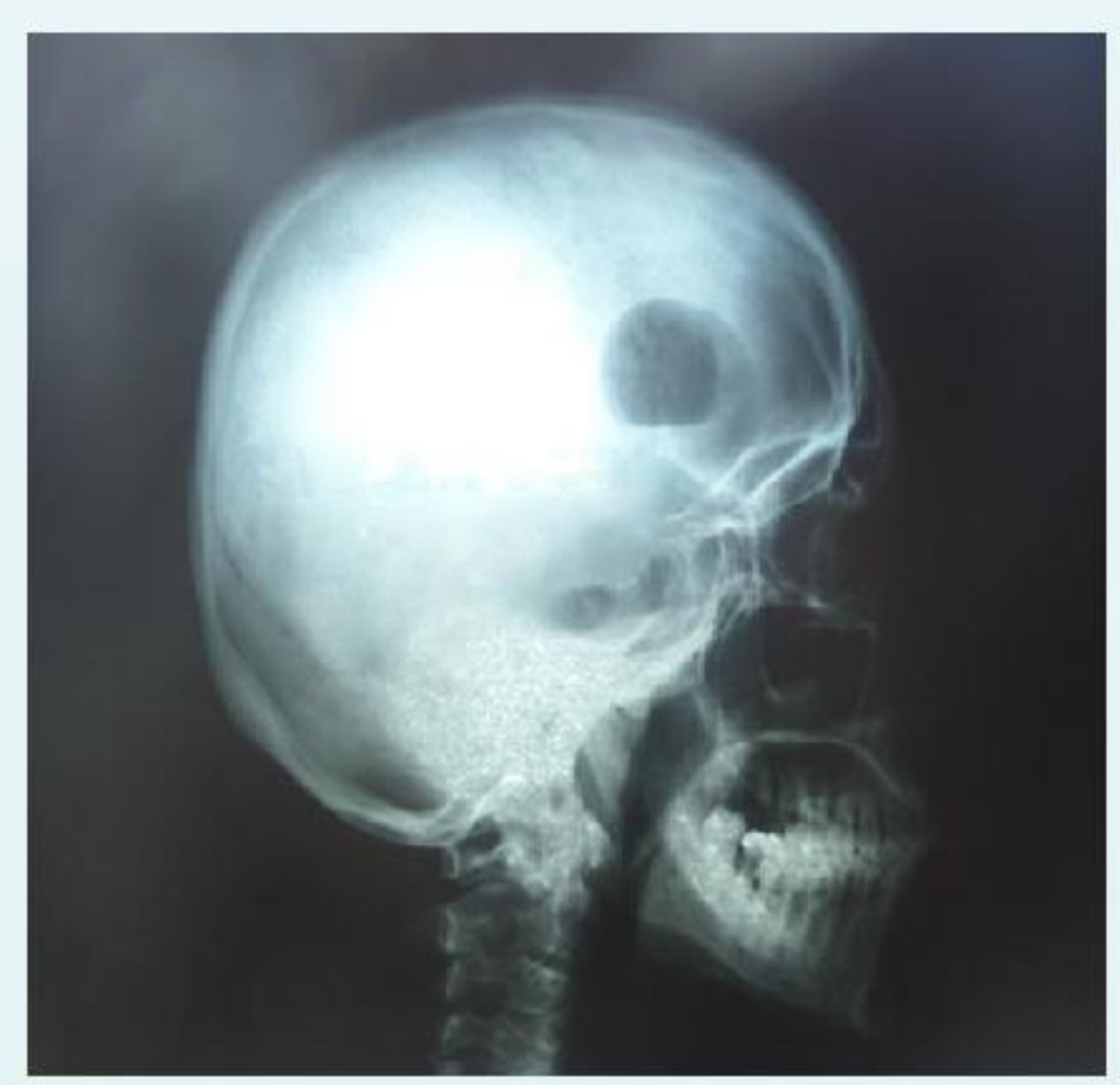

\section{CASE REPORT}

A 39-year-old man presented in the emergency department with significant visual loss, headache and rhinorrhea.

He had no previous history of head trauma or medical illnesses.

He complained for increasing fatigue, headache and progressive loss of libido for the last 20 years.

\section{MEDICAL HISTORY}

His medical history was significant for delayed and incomplete puberty.

He also mentioned early discharge from the armed forces (due to hypogonadism)

\section{CLINICAL EXAMINATION}

His height was $160 \mathrm{~cm}$. He had low blood pressure, orthostasis and diminished pubic, axillary, and secondary sexual facial hair. His testicular volume was $3 \mathrm{ml}$ and he had micropenis. Optical field examination revealed preservation of central vision only.

\section{LABORATORY VALUES AND HORMONE MEASUREMENTS}

\begin{tabular}{|c|c|c|c|c|}
\hline Hgb & $10 \mathrm{~g} / \mathrm{dl}$ & Hormone & Value & Normal Range \\
\hline \multirow{2}{*}{ Glu } & \multirow{2}{*}{$102 \mathrm{mg} / \mathrm{dl}$} & PRL & 80 & $1,8-16 \mathrm{ng} / \mathrm{mL}$ \\
\hline & & TSH & 0,3 & $0,4-3,1 \mu \mathrm{IUml}$ \\
\hline $\mathrm{Cr}$ & $0,7 \mathrm{mg} / \mathrm{dl}$ & FT4 & 0,5 & $0,9-2,2 \mathrm{ng} / \mathrm{dl}$ \\
\hline $\mathbf{N a}$ & $143 \mathrm{meq} / \mathrm{L}$ & ACTH & 3 & $5-46 \mathrm{pg} / \mathrm{ml}$ \\
\hline $\mathbf{K}$ & $4,4 \mathrm{meq} / \mathrm{L}$ & Cortisol & 5 & $6-23 \mu \mathrm{g} / \mathrm{dl}$ \\
\hline \multirow[t]{2}{*}{ Urine Vol } & \multirow[t]{2}{*}{$2000 \mathrm{ml} / 24 \mathrm{~h}$} & FSH & 0,1 & 0,9--8,9 mIU/ml \\
\hline & & LH & 0,6 & 0,8-10 mIU/ml \\
\hline SG & 1020 & FTesto & $<9$ & $9-41 \mathrm{pg} / \mathrm{ml}$ \\
\hline
\end{tabular}

\section{BRAIN MRI}

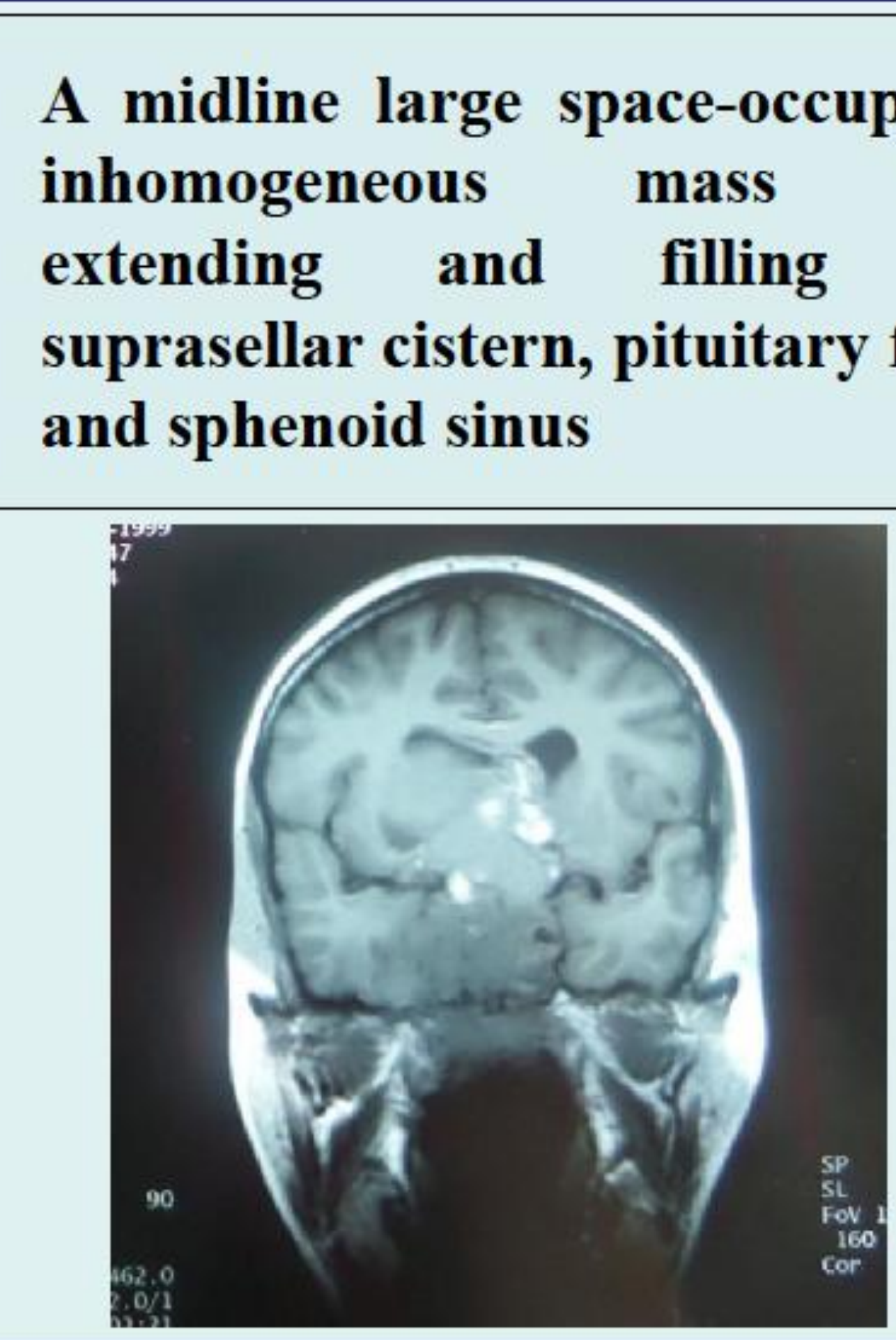

$$
\begin{array}{|}
\hline \\
\hline
\end{array}
$$
these patients.
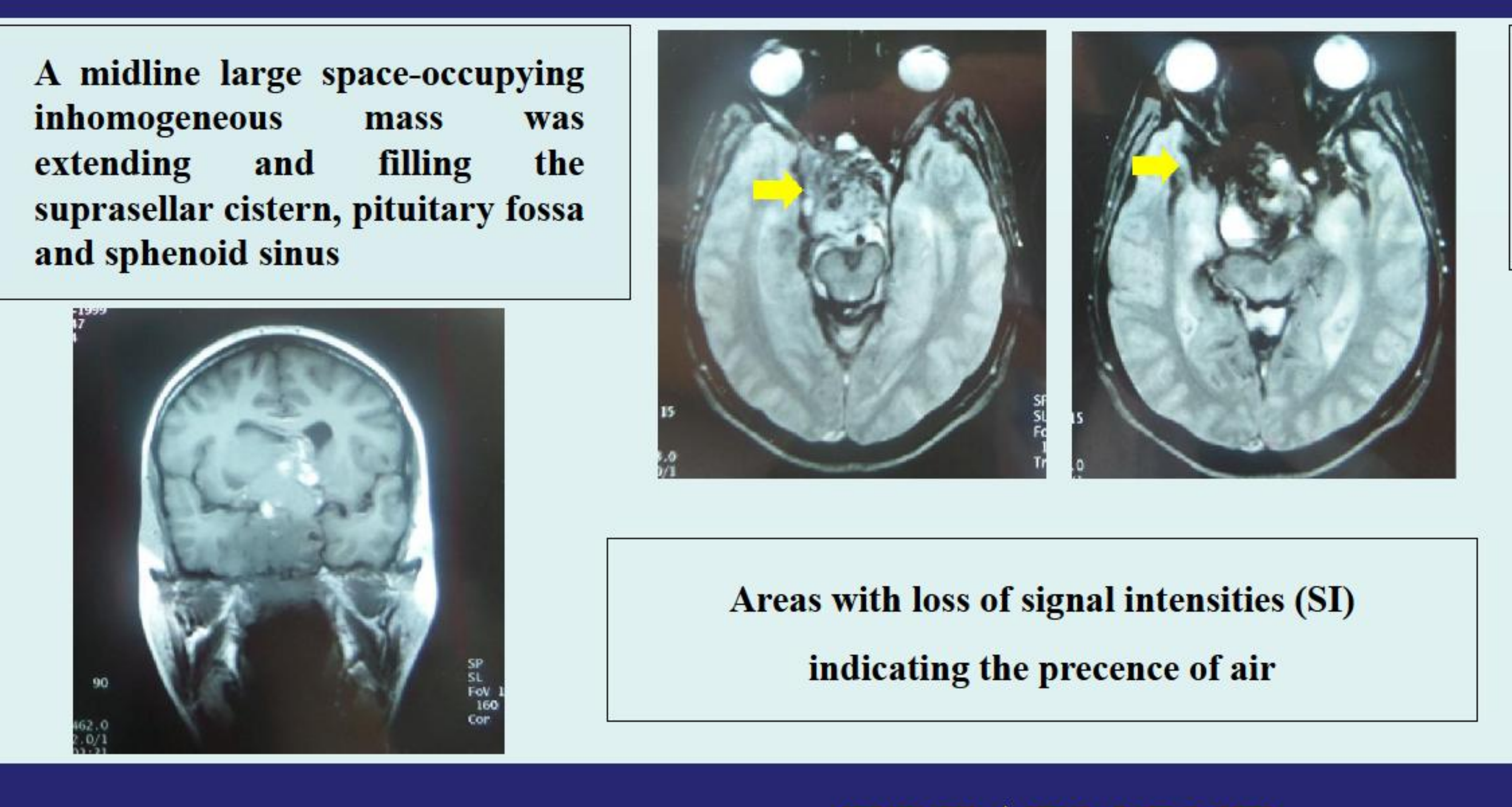

Areas with loss of signal intensities (SI) indicating the precence of air

\section{TREATMENT}

The patient underwent neurosurgical debulking of the tumor and was placed in hormone replacement therapy with marked improvement

\section{CONCLUSIONS}

Although extremely rare, a spontaneous pneumocephalus should be considered as a possible diagnosis in patients with large pituitary lesions, rhinorrhea and non-specific neurological manifestations. Early treatment of this potentially life-threatening disorder improves surveillance of
A hypointence rim representing hemosiderin deposition at the pial meninger

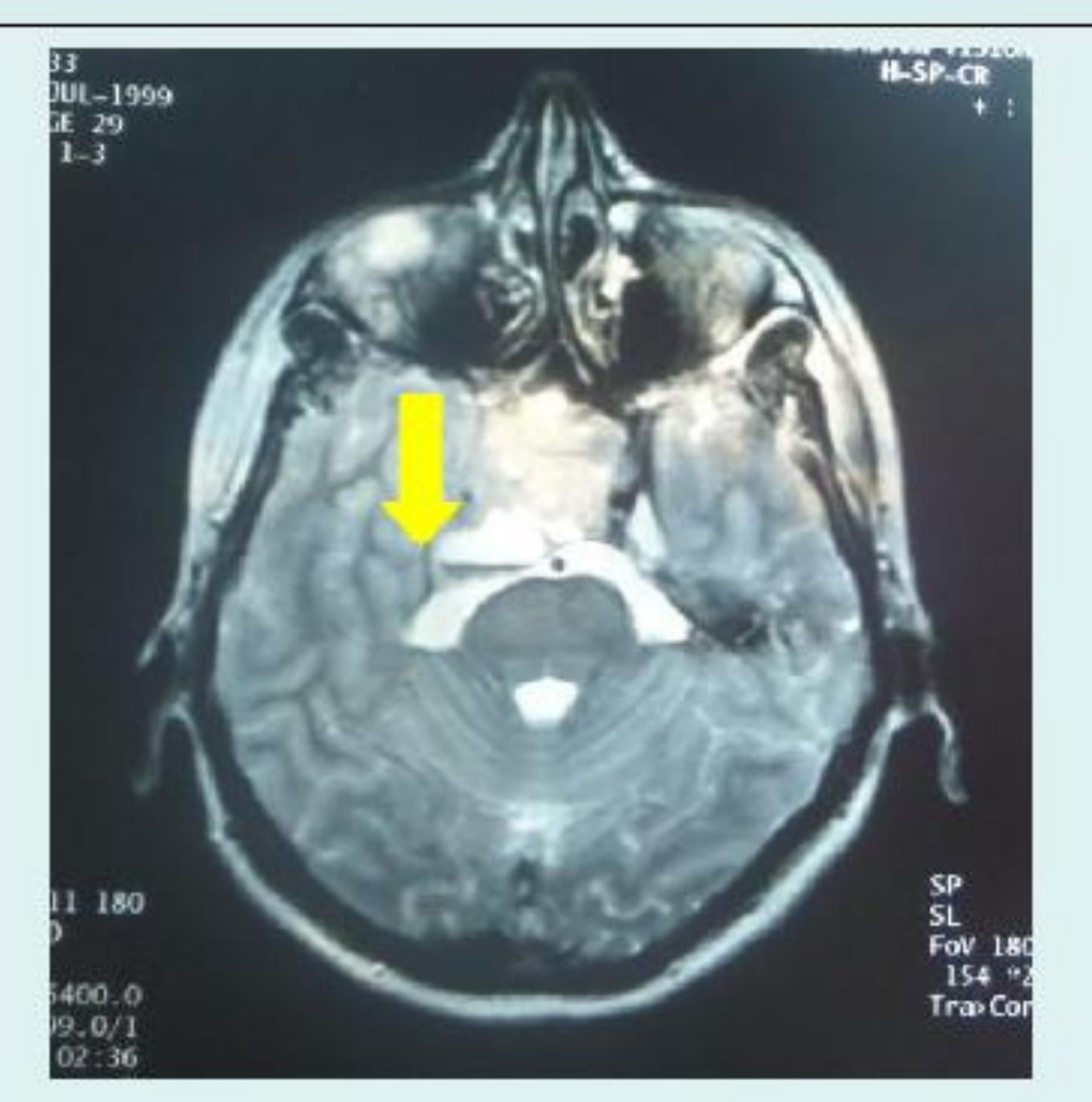

.
\section{(1)}

